\title{
Empirical Estimation of Accumulation-Induced Change in Gill Net Catch- ability: Mind the Observation Errors
}

\author{
Timo J. Marjomäki ${ }^{1, *}$, Marko Paloniemi $^{2}$, Tapio Keskinen ${ }^{3}$, Jonna Kuha $^{1}$ and Juha Karjalainen ${ }^{1}$
}

${ }^{1}$ University of Jyväskylä, Department of Biological and Environmental Science, P.O.Box 35, 40014 University of
Jyväskylä, Finland; ${ }^{2}$ Etelä-Pohjanmaan Kalatalouskeskus ry, Huhtalantie 2, 60220 Seinäjoki, Finland; ${ }^{3}$ Natural
Resources Institute Finland; Survontie 9 A, 40500 Jyväskylä, Finland

\begin{abstract}
We analyzed cumulative catches for 24 h gill net exposures divided into $4 * 6 \mathrm{~h}, 2 * 12 \mathrm{~h}$ and $1 * 24 \mathrm{~h}$ soak time treatments to estimate the reduction in its catchability due to accumulation of fish. The effects of loss of catch during net lifting, disturbance effect and fouling were eliminated as far as possible to reveal the true effect of accumulation. First we applied simple nonparametric and parametric tests in comparison of treatments. As expected, considerable reduction in catchability took place along with the increase in soak time, indicated by significantly lower total $24 \mathrm{~h}$ catches from longer soaks in comparison with shorter ones. The reduction was more pronounced for roach than for perch. Further, we compared a functional relationship regression (FRR), admitting correctly observation error variance also in the $\mathrm{x}$-axis variable, with ordinary least squares regression (OLS) in modelling the relationship between cumulative $24 \mathrm{~h}$ catches for different treatments. We estimated the between-replicates proportional observation error variance within a treatment and found it to be similar in different treatments. Therefore the variance ratio could be assumed to be close to 1 enabling the use of major axis solution FRR. In this particular case the incorrect use of OLS obviously gives a seriously biased result, exacerbating the negative effect of accumulation for high $\mathrm{x}$-axis values in comparison with FRR. We recommend the use of FRR for any analysis comparing different notoriously low precision fish abundance proxies.
\end{abstract}

Keywords: Accumulation, bias, catchability, error in variables, saturation.

\section{INTRODUCTION}

In Europe, standardised gillnetting is a common method for monitoring changes in abundance of fish populations and fish community structure [1]. It is also a key method in the assessment of the ecological status of lakes [2]. The basic assumption for unbiased monitoring of relative changes in population abundance using catch per unit effort (CPUE) is that the catchability of the gear is a density-independent constant, and contains as little as possible random variation due to other density-independent factors [3,4]. Thus, abundance and its index should be directly proportional to each other. Unfortunately, this assumption typically does not hold for passive gill nets. Several studies [5-10] have reported a negative relationship between gill net catchability and abundance, and consequently CPUE may even appear asymptotically related to abundance.

One of the reasons for this phenomenon is the effect of fish accumulation in a gill net (see review [11] and references therein). Many causal mechanisms, both biological and technical, have been suggested: 1) fish are repulsed around a captured, possibly dead individual $[12,13]$; 2) easier visual detection of the net due to caught fish [12]; 3) space limitation whereby once a fish has been captured, a certain area surrounding it is no longer capable of catching

*Address correspondence to this author at the University of Jyväskylä, Department of Biological and Environmental Science, P.O.Box 35, 40014 University of Jyväskylä, Finland; Tel: +358 50428 5274;

E-mail: timo.j.marjomaki@jyu.fi fish [14]. Changes in the hanging ratio and decrease in flexibility may also decrease catchability [15]. Even a small catch can reduce the catchability of a gill net [15].

One consequence of fish accumulation-induced decrease in catchability is that the gill net catch is not proportional to duration of fishing (set time, soak time) but has been suggested to increase with decreasing rate [16, 12]. Kennedy [12] suggested that it is possible to "saturate" nets so that they will not catch fish any more, i.e. catchability approaches zero (note, however, that part of this decrease may be due to fouling of net twine with algae or silt $[17,18])$. Saturation is suggested to happen at rather low proportional catches, when only a few percent of meshes are occupied by fish $[19,15]$. Thus, in the case of a long soak time, the catch may be rather constant, and independent of abundance; only the rate of accumulation, which cannot be observed, varies. Therefore, it is essential to use short soak time and suitable times of day (e.g. [15]).

There are different ways of studying the effect of soak time on gill net CPUE. A direct approach is to observe CPUE as a function of soak time, either from catch statistics [12] or by multiple inspections of nets during the catching process [10]. However, a common approach is to set standard gill nets simultaneously into as homogenous as possible habitat for different soak times with replacement, and then calculate the cumulative catch over a longer period, e.g., comparing soak times $1 * 24 \mathrm{~h} v s .2 * 12 \mathrm{~h} v$ s. $4 * 6$ h etc. e.g., $[15,20]$. It has typically been observed in such experiments that one longer soak yields lower catches than several shorter 
soaks for the same total exposure period. At high fish density or activity this phenomenon occurs within a few hours or even less. If the exposures are made in locations of different fish densities and/or activity periods (e.g., daily, seasons with different temperatures), the effect of fish density on accumulation effect or, more precisely applying the terminology of Prchalová et al. [10,20], fish density rate can be estimated.

Typically, these field experiment data from different soak times have been statistically approached by fitting a nonlinear regression model between cumulative CPUE for shorter soak time as "independent" variable (x-axis) and longer soak time CPUE as "dependent" variable (y-axis) e.g., [15]. It is important to acknowledge in this regression approach 1) that the two variables are "equal" and thus not in any sense "independent" and "dependent" and 2) that both variables, as with fisheries data in general, are estimates that may contain considerable observation error due to random variation, either measurement error or natural variability. This contradicts the fundamental assumption of the ordinary least squares regression (OLS) that the independent variable is measured without error and thus all error is a result of observing the dependent variable. In practice, the OLS regression is rather robust to random error in $\mathrm{x}$-axis variable if it is low relative to the error in y-axis variable, but this precondition is not met in the context of regressing two gill net CPUEs, equally prone to high random error. The random error within the measurements of the $\mathrm{x}$-axis variable distributes the observations artificially widely in the horizontal scale. As a consequence, the fitted OLS regression curves become biased; in the special case of linear regression the slope is biased towards zero [21] and in the case of curve fitting the tendency for asymptotical curvature is exacerbated [22]. In the case of CPUEs, this may lead to systematic underestimation of the level of the asymptote (y-axis) and the level of the $\mathrm{x}$-axis variable at which this asymptote (i.e. saturation) is reached. To eliminate or at least decrease these biases, measurement error models, such as functional relationship regression (FRR) models, should be applied, as advocated by Kimura [23]. Fitting of a FRR model is a straightforward task, but to be successful requires that the variances of random errors, variances of individual observations around some unknown true values of both variables, or at least the ratio of these variances, is known. These are typically unknown but can be assessed by replicated observations corresponding to one or more values of the variables [24].

In this study, we analyse a dataset from a field experiment applying different gill net soak times for estimating cumulative catch per unit effort $(U)$ of $24 \mathrm{~h}$ exposure. Firstly, we apply robust nonparametric and parametric tests to show the existence of a negative effect of accumulation on catchability. Then we fit functional relationship regression models in an attempt to quantify the effect of accumulation without much bias. To achieve this, we estimate the variances of random errors in catch per unit effort observations.

\section{MATERIALS AND METHODOLOGY}

\section{Study Area}

The gill netting experiment was carried out in Lake Jyväsjärvi, Finland $\left(62^{\circ} 14^{\prime} \mathrm{N}, 25^{\circ} 46^{\prime} \mathrm{E}\right)$. The area of the lake is $3.4 \mathrm{~km}^{2}$, mean depth $7 \mathrm{~m}$ and maximum depth $25 \mathrm{~m}$. L. Jyväsjärvi is mesotrophic with total phosphorus concentration during summer typically $25-30 \mu \mathrm{g} \mathrm{l}^{-1}$, chlorophyll a $10-13 \mu \mathrm{g} \mathrm{l}^{-1}$ and total nitrogen $700 \mu \mathrm{g} \mathrm{l^{-1 }}$. The Secchi depth varies during the open water season between 1.4 and $2 \mathrm{~m}$ and the water colour is around $80 \mathrm{mg} \mathrm{Ptl}^{-1}$. The dominant species in the fish assemblage are perch (Perca fluviatilis L.) and roach (Rutilus rutilus (L.)), comprising $>80 \%$ of gillnet catch per unit effort [25].

\section{Gillnets}

We used multi mesh gillnets specially designed and standardised for fish monitoring. The length of the net is $30 \mathrm{~m}$ (upper rope $27 \mathrm{~m}$, lower $33 \mathrm{~m}$ ) and height $1.5 \mathrm{~m}$. The net consists of 9 panels of $3.3 \mathrm{~m}$ in length and area of $5 \mathrm{~m}^{2}$ with different mesh sizes from 10 to $55 \mathrm{~mm}$ from knot to knot (Table 1) in randomised order. The mesh sizes closely obey a geometric series progression (ratio between consecutive mesh sizes constant, in this case from 1.17 to 1.33 ) and thus it can be expected that the net is fairly unselective towards fish length [26].

Table 1. Properties of multimesh gill nets used in experiment in Lake Jyväsjärvi. The number of meshes in each panel was calculated by: number of meshes horizontally*number of meshes vertically * 2 .

\begin{tabular}{|c|c|c|}
\hline Mesh Size, mm & Twine Thickness, mm & Number of Meshes \\
\hline \hline 10 & 0.15 & 59940 \\
\hline 12 & 0.15 & 41978 \\
\hline 15 & 0.15 & 27084 \\
\hline 20 & 0.15 & 15364 \\
\hline 25 & 0.17 & 9443 \\
\hline 30 & 0.17 & 6771 \\
\hline 35 & 0.17 & 5130 \\
\hline 45 & 0.20 & 2660 \\
\hline 55 & 0.20 & 1891 \\
\hline
\end{tabular}

\section{Experiment}

We carried out $24 \mathrm{~h}$ fishing sessions repeated 23 times between June 28 and September 29 to study the effect of accumulation. We selected the locations for different sessions, based on the previous knowledge, to collect observations from different fish densities. During every session, we set three nets at noon within one location in the littoral zone that was as homogenous as possible regarding depth and vegetation. The nets were set in a row parallel to the shoreline and $30-50 \mathrm{~m}$ apart. Based on previous experience, we considered this distance sufficient for making the catches independent of each other. A greater distance would have compromised the assumption of homogeneity of the habitat. One of the nets was set for $24 \mathrm{~h}$ (treatment $1 * 24 \mathrm{~h}$ ), one was replaced with a new one after $12 \mathrm{~h}$ (treatment $2 * 12 \mathrm{~h}$ ) and one was replaced after every 6 hours (treatment $4 * 6 \mathrm{~h}$ ). We 
randomised the order of treatments in the row of nets for every session. During every replacement, thus at 6 hour intervals, we lifted every net that was not replaced above the surface and sunk again. This procedure was carried out because: 1) It compensates for the loss of caught fish during lifting process by making the number of lifts for each treatment equal during the $24 \mathrm{~h}$ period; 2 ) It makes the amount of disturbance equal for every treatment; and 3) It cleans the net twines from debris thus equalizing the loss of catchability due to fouling for every treatment. Regarding justification 1) above we must emphasise the fact that although the fish that were caught in the very beginning of longer treatments obviously experienced several liftings, we assumed, based on our previous observations, that the fish that had been struggling in the net for longer than 6 hours would have got entangled to an extent that they would not get released later. Thus, we assume that the fish that have a chance of getting released must have been caught during the last $6 \mathrm{~h}$ period before lifting. However, the number of fish escaping in lifting was so marginal that this assumption has no practical effect on the results. But see [10] for a proper method for short exposures.

Temperature varied between 12 and $25{ }^{\circ} \mathrm{C}$ during the study, the number of daylight hours from 19 to $11 \mathrm{~h} \mathrm{~d}^{-1}$ and weather from sunny to rainy, so that the catches represent not only the actual fish density but the product of density, temperature, illumination and weather related activity. However, it was assumed that the product, cumulative catch in 24 $\mathrm{h}$, responded uniformly to the accumulation effect despite the uncontrolled variation in factors of the product. No symptoms of different responses (e.g. odd residual correlations with any of the above mentioned uncontrolled factors) were detected in the analysis.

We removed catches from the nets immediately after each gear replacement/maintenance trip and recorded the number and total fresh weight of each species from every panel separately.

We assessed the observation error variance within different treatments by replicating each soak time treatment simultaneously in a homogenous habitat for $24 \mathrm{~h}$. The numbers of replicates were 4 for treatment $1 * 24 \mathrm{~h}$ and 3 for $2 * 12 \mathrm{~h}$ and $4 * 6 \mathrm{~h}$.

\section{Statistical Analysis}

\section{Variables}

We calculated the total number of fish caught during the $24 \mathrm{~h}$ unit effort in each treatment separately for each panel of different mesh size and used this variable in the further analysis as a unit observation. Unavoidably, catches from different mesh sizes correlated with each other within treatment between sessions; i.e. if there was an exceptionally high catch in the $12 \mathrm{~mm}$ panel in the $1 * 24 \mathrm{~h}$ gillnet in a certain session, the $15 \mathrm{~mm}$ panel also yielded an exceptionally high catch. Thus, the observations were not completely independent of each other. This may lead in certain tests to artificially high degree of freedom. To avoid this bias, we performed several tests also for total catch per unit effort from all mesh sizes.

We limited the mesh size specific statistical analysis to observations from mesh sizes 10-30 mm. Larger meshes were omitted because their cumulative catches in $24 \mathrm{~h}$ were very low, with more than $50 \%$ of the catches being 0 , and a maximum of only 6 individuals. Zero catches were also omitted from analysis for other mesh sizes (for $20 \mathrm{~mm} 1$

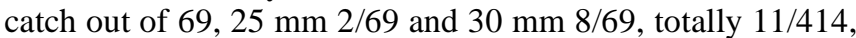
$2.7 \%$ ) because we considered those cases to be below measurement sensitivity.

To make all results comparable, we scaled the catches per unit of effort $(U)$ proportional to one million meshes in each panel by

$P U_{\mathrm{m}, \mathrm{t}, \mathrm{i}}=U_{\mathrm{m}, \mathrm{t}, \mathrm{i}} / N_{\mathrm{m}} * 1000000$,

where $P U_{\mathrm{m}, \mathrm{t}, \mathrm{i}}=$ proportional catch per unit of effort for mesh size $\mathrm{m}$, treatment $\mathrm{t}$ and session $\mathrm{i}, U_{\mathrm{m}, \mathrm{t}, \mathrm{i}}=$ number of fish caught in $24 \mathrm{~h}$ and $N_{\mathrm{m}}=$ number of meshes in panel of mesh size $\mathrm{m}$ (from knot to knot).

We $\log _{10}$-transformed all values routinely in order to standardise and normalise error variance in model fitting.

$P U_{\mathrm{m}, \mathrm{t}, \mathrm{i}}$ is comparable to the commonly used index "percentage of meshes occupied" so that the values of $P U_{\mathrm{m}, \mathrm{t}, \mathrm{i}}=1000$ and $\log P U_{\mathrm{m}, \mathrm{t}, \mathrm{i}}=3$ correspond to $1 \%$ of meshes occupied.

Whenever total catch from all meshes (including all the mesh sizes and also zero catches) was used in any analysis, it was calculated as an average percentage from the values of different mesh sizes.

$$
\text { TotalP } U_{\mathrm{t}, \mathrm{i}}=\operatorname{sum}\left(P U_{\mathrm{m}, \mathrm{t}, \mathrm{i}}\right) / 9
$$

\section{A Nonparametric Test for Accumulation Effect}

If accumulation induces a negative effect on catchability, then it can be hypothesised $\left(\mathrm{H}_{1}\right)$ that longer continuous soak time yields typically lower catch than the equally long total exposure consisting of several shorter soak times. The pairs of observations were, therefore, binary coded:

$X=1$ if $U_{\mathrm{m}, \mathrm{t}, \mathrm{i}}$ for longer soak time treatment was lower than that from shorter soak time treatment and

$X=0$ in opposite case.

According to the $\mathrm{H}_{0}$-hypothesis of no effect, the binary observations should obey an even (50:50) distribution. We applied a simple $\chi^{2}$-test to assess whether the observed distribution for certain pair of treatments deviated significantly from this.

\section{A Parametric Test for Accumulation Effect}

We applied a pairwise $t$-test with the session (date) as the classifying factor to test the significance of difference in TotalP $U_{\mathrm{t}, \mathrm{i}}$ from all pairs of treatments.

As above if accumulation induces negative effect on catchability, then it can be hypothesised $\left(\mathrm{H}_{1}\right)$ that the

$$
\text { average }\left[\log \left(\text { TotalP }_{\mathrm{Y}, \mathrm{i}}\right)-\log \left(\text { TotalP }_{\mathrm{X}, \mathrm{i}}\right)\right]<0 \text {, }
$$

where $\mathrm{Y}$ is longer exposure treatment and $\mathrm{X}$ is shorter.

We also tested whether the general result was different for different mesh sizes $\left(\mathrm{H}_{1}\right.$ : interaction term for treatment*mesh size significant) using repeated measures ANOVA with mesh size as within subject factor. Repeated measures and pairwise tests were selected because the study desing was based on the idea of measuring the same vari- 
able, average density in particular site in particular moment with three different "measurement devices" i.e., exposure treatments.

\section{Modelling}

We applied the power function, one of the simplest nonlinear functions, in model fitting between treatments:

$P U_{\mathrm{m}, \mathrm{Y}, \mathrm{i}}=\mathrm{a} * P U_{\mathrm{m}, \mathrm{X}, \mathrm{i}}^{\mathrm{b}}$

where $\mathrm{a}$ and $\mathrm{b}$ are regression coefficients and subscripts $\mathrm{Y}$ and $\mathrm{X}$ denote different treatments. If accumulation has no effect $\mathrm{a}$ and $\mathrm{b}$ have $\mathrm{a}$ value of 1 and the function simplifies to

$P U_{\mathrm{m}, \mathrm{Y}, \mathrm{i}}=P U_{\mathrm{m}, \mathrm{X}, \mathrm{i}}$

Taking the logarithmic form of equation 2 , the model becomes linear

$\log P U_{\mathrm{m}, \mathrm{Y}, \mathrm{i}}=\log (a)+b * \log P U_{\mathrm{m}, \mathrm{X}, \mathrm{i}}$

The parameter estimates $\log (a)$ and $b$ for OLS-regression were estimated in a standard way. The parameter estimates for linear functional relationship regression (FRR) are [21, 23]:

$b=\left(\left(s_{y}{ }^{2}-\lambda s_{x}{ }^{2}\right)+\left(\left(s_{y}{ }^{2}-\lambda s_{x}{ }^{2}\right)+4 \lambda s_{x y}{ }^{2}\right)^{0.5}\right) /\left(2 s_{x y}\right)$,

where

$\lambda=\sigma_{\varepsilon}^{2} / \sigma_{\delta}^{2}$

$\log (a)=\underline{\mathrm{Y}}-\underline{\mathrm{X}} b$

where $s_{y}{ }^{2}, s_{x}{ }^{2}$ and $s_{x y}$ are sample variances and covariance of $\log P U_{\mathrm{m}, \mathrm{Y}, \mathrm{i}}$ and $\log P U_{\mathrm{m}, \mathrm{X}, \mathrm{i}}$ and $\underline{Y}$ and $\underline{X}$ are their sample means.

$\sigma_{\varepsilon}^{2}$ and $\sigma_{\delta}^{2}$ are the estimates of observation error variances of $\mathrm{Y}$ - and $\mathrm{X}$-axis variables, respectively. These were estimated from the data of simultaneous replicates of every treatment by $\sigma_{\mathrm{t}}^{2}=\left(\log P U_{\mathrm{m}, \mathrm{t}, \mathrm{j}}-\underline{\log P U_{m, t}}\right)^{2} /(\mathrm{n}-1)$

where $\log P U_{\mathrm{m}, \mathrm{t}, \mathrm{j}}$ is the $\mathrm{j}:$ th replicate observation for mesh $\mathrm{m}$ and treatment $\mathrm{t}$ and $\underline{\log P U_{\mathrm{m}, \mathrm{t}}}$ is the sample mean of all replicates for treatment $t$.

To illustrate the effect of functional form on the difference between OLS and FRR we fitted also an asymptotic model

$\log P U_{\mathrm{m}, \mathrm{Y}, \mathrm{i}}=\log \left(1 /\left(1 / \mathrm{a}+\mathrm{b} / P U_{\mathrm{m}, \mathrm{X}, \mathrm{i}}\right)\right.$

for different values of $\lambda$ using the iterative method described by Kimura (2000) [23].

\section{RESULTS}

\section{Total Catch and Species Distribution}

Altogether 10428 individuals, $296 \mathrm{~kg}$ and 12 species were caught during the 23 fishing sessions of $24 \mathrm{~h}$ with three treatments (Table 2). The majority of the catch (individuals) consisted of perch, with roach the second most common species. Together these species formed over $90 \%$ of the catch. Regarding yield (catch in mass units), roach was the most abundant species and perch second, together constituting almost $90 \%$ of total yield.

\section{Nonparametric Frequency Difference Approach}

In comparison to even distribution of ranks, the $24 \mathrm{~h}$ catches per unit effort from the $1 * 24 \mathrm{~h}$ and $2 * 12 \mathrm{~h}$ soak time treatments were significantly more often lower than that for the $4 * 6$ h treatment (Table 3, Figs. (1-3) division of observation on different sides of $\mathrm{Y}=\mathrm{X}$ line), showing that fish accumulation clearly reduced gill net catchability. The result was consistent for both individual $10-30 \mathrm{~mm}$ panels and the average for the whole gillnet. The treatment $1 * 24 \mathrm{~h}$ typically also yielded lower catches than $2 * 12 \mathrm{~h}$ but the result was not as pronounced as for the comparison with $4 * 6 \mathrm{~h}$.

Table 2. The catch (individuals), yield (kg) and mean mass of different fish species caught from Lake Jyväsjärvi during the experiment.

\begin{tabular}{|c|c|c|c|c|c|c|}
\hline Common Name & Scientific Name & Catch & $\%$ & Yield & $\%$ & Mean Mass, $\mathrm{g}$ \\
\hline Perch & Perca fluviatilis $\mathrm{L}$. & 6955 & 66.7 & 108.1 & 36.5 & 16 \\
\hline Roach & Rutilus rutilus (L.) & 2844 & 27.3 & 148.9 & 50.3 & 52 \\
\hline Bleak & Alburnus alburnus (L.) & 218 & 2.1 & 3.6 & 1.2 & 17 \\
\hline Ruff & Gymnocephalus gernuus (L.) & 153 & 1.5 & 1.4 & 0.5 & 9 \\
\hline Bream & Abramis brama (L.) & 91 & 0.9 & 12.0 & 4.1 & 132 \\
\hline Pike-perch & Sander lucioperca (L.) & 84 & 0.8 & 13.6 & 4.6 & 162 \\
\hline Silver bream & Abramis bjoerkna (L.) & 43 & 0.4 & 1.7 & 0.6 & 40 \\
\hline Whitefish & Coregonus lavaretus (L.) & 25 & 0.2 & 2.6 & 0.9 & 104 \\
\hline Smelt & Osmerus eperlanus (L.) & 9 & 0.1 & 0.1 & $<0.1$ & 11 \\
\hline Pike & Esox lucius L. & 4 & $<0.1$ & 2.4 & 0.8 & 600 \\
\hline Rudd & Scardinius erythropthalmus (L.) & 1 & $<0.1$ & 0.1 & $<0.1$ & 100 \\
\hline Brown trout & Salmo trutta $\mathrm{L}$. & 1 & $<0.1$ & 1.6 & 0.5 & 1600 \\
\hline Total & & 10428 & & 296.1 & & 28 \\
\hline
\end{tabular}


Table 3. Results for the $\chi^{2}$-test for $H_{1}$ : the proportional cumulative $24 \mathrm{~h}$ catch per unit effort for a longer soak time treatment is lower than that of a shorter one. Roman numerals refer to treatments.

\begin{tabular}{|c|c|c|c|c|c|c|}
\hline Data & Treatment I vs. II & I $<$ II & I $>$ II & $\mathbf{n}$ & $\chi^{2}$ & $\mathbf{p}$ \\
\hline $10-30 \mathrm{~mm}$ meshes individually & $2 * 12 \mathrm{~h} v s .4 * 6 \mathrm{~h}$ & 75 & 54 & 129 & 3.42 & 0.064 \\
\hline \multirow{2}{*}{ Total catch } & $1 * 24 \mathrm{~h} v s .4 * 6 \mathrm{~h}$ & 17 & 6 & 23 & 5.26 & 0.022 \\
\hline & $2 * 12 \mathrm{~h} v s .4 * 6 \mathrm{~h}$ & 17 & 6 & 23 & 5.26 & 0.022 \\
\hline
\end{tabular}

Table 4. Results for the pairwise $t$-test for one-tailed $\mathrm{H}_{1}$ : the mean difference between $\log$ of catch per unit effort (logPU) for the 24 $h$ fishing period for longer soak times and shorter ones is negative. Mean ratio is the geometric mean of the ratio between longer and shorter soak time $U: s\left(\right.$ note: difference $\log (y)-\log (\mathbf{x})=\log (\mathbf{y} / \mathbf{x})$ and thus Mean ratio $\left.=10^{\text {mean }(\log (\mathbf{y} / \mathbf{x}))}\right)$.

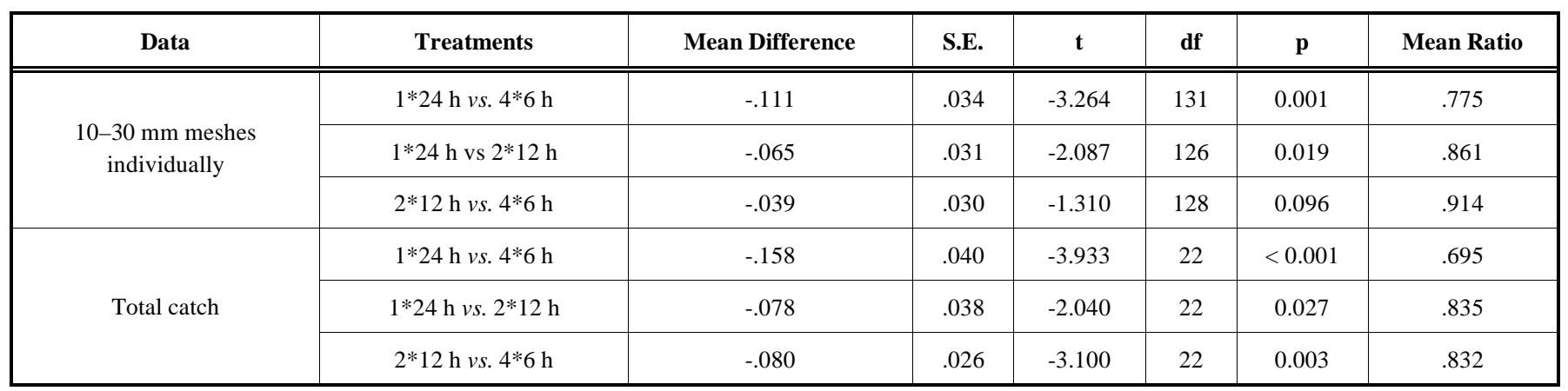

Table 5. The total catches of perch and roach during the $24 \mathrm{~h}$ fishing period and their proportions of total catch from different soak time treatments is shown below.

\begin{tabular}{|c|c|c|c|c|c|c|}
\hline Species & \multicolumn{3}{|c|}{ Individuals } & \multicolumn{3}{c|}{ Catch \% } \\
\hline & $\mathbf{4 * 6} \mathbf{~ h}$ & $\mathbf{2 * 1 2} \mathbf{~ h}$ & $\mathbf{1 * 2 4} \mathbf{~ h}$ & $\mathbf{4 * 6 \mathbf { h }}$ & $\mathbf{2 * 1 2} \mathbf{~ h}$ & $\mathbf{1} * \mathbf{2 4} \mathbf{h}$ \\
\hline \hline Perch & 2493 & 2422 & 2040 & 65.9 & 69.4 & 73.1 \\
\hline Roach & 1221 & 937 & 686 & 27.8 & 24.5 & 22.5 \\
\hline
\end{tabular}

\section{Parametric Quantitative Difference Approach}

Quantitative pairwise comparison of the $\log P U$ values between longer and shorter soak time treatments indicated that the longer soak gillnets yielded lower catches than shorter soak ones (all one-tailed p-values $<0.1$, Table 4 ). The catches for the longest $1 * 24 \mathrm{~h}$ soak treatment were on average 20-30\% lower than that of the shortest $4 * 6 \mathrm{~h}$ soak treatment. The difference between $1 * 24 \mathrm{~h}$ and $2 * 12 \mathrm{~h}$ and between $2 * 12 \mathrm{~h}$ and $4 * 6 \mathrm{~h}$ was typically less, as expected, but was still significant. The highest catches of the longest soak time $(1 * 24 \mathrm{~h})$ were also clearly lower than those of shorter soak times (Figs. 1-3).

The repeated measures ANOVA with mesh size as within-subject factor revealed that the general result was not different for different mesh sizes, because interaction treatment of the*mesh size was not significant ( $\mathrm{p}>0.1$ ).

The soak time treatment had a significant effect on the proportions of the two most common species (Table 5) (Re- peated measures ANOVA: Perch $\mathrm{F}=6.48$, df = 2, $\mathrm{p}=0.003$; Roach $F=4.29$, df $=2, p=0.02$ ). The proportion of perch increased with the increase in soak time (pairwise comparison $4 * 6 \mathrm{~h} v s .1 * 24 \mathrm{~h} \mathrm{p}=0.003)$ and that of roach decreased (pairwise comparison $4 * 6 \mathrm{~h} v s .1 * 24 \mathrm{~h} \mathrm{p}=0.012$ ). Although the catch in number of both species declined with the increase in soak time, the decrease was more marked of roach than of perch. Thus, the catchability of roach seems to be more sensitive to the accumulation than that of perch.

\section{Modelling Approach}

For the application of a functional relationship regression (FRR), we first estimated the observation error variances for different treatments. The coefficient of variation of $\log P U$ between simultaneous replicates from one site varied considerably for different mesh sizes but without any trend related to mesh size (Table 6), even though the geometric means for different treatments were almost identical at $5-6 \%$. This corresponds to a percentile deviation from the mean in the 
original $U$-data of $-24 \%$ or $+32 \%$; thus assuming a log of normal distribution of measurements, $66 \%$ of $U$ observations were within the range and $76-132 \%$ of the mean.

Table 6. The coefficient of variation (C.V. = S.D./mean) of $\log P U$ between replicates for different soak time treatments.

\begin{tabular}{|c|c|c|c|}
\hline Mesh Size & \multicolumn{3}{|c|}{ C.V. for Treatment } \\
\hline $\mathbf{m m}$ & $\mathbf{1} \mathbf{2 4} \mathbf{h}$ & $\mathbf{2} * \mathbf{1 2} \mathbf{~ h}$ & $\mathbf{4} * \mathbf{6} \mathbf{~ h}$ \\
\hline & $\mathbf{n = 4}$ & $\mathbf{n = 3}$ & $\mathbf{n = 3}$ \\
\hline \hline 10 & 0.17 & 0.15 & 0.03 \\
\hline 12 & 0.04 & 0.02 & 0.05 \\
\hline 15 & 0.02 & 0.01 & 0.05 \\
\hline 20 & 0.03 & 0.08 & 0.06 \\
\hline 25 & 0.12 & 0.06 & 0.07 \\
\hline 30 & 0.10 & 0.12 & 0.06 \\
\hline GM & 0.06 & 0.05 & 0.05 \\
\hline
\end{tabular}

The variance ratios $\lambda$ for different mesh sizes and pairs of treatments also varied considerably (Table 7). However, the geometric mean for every pair was very close to unity, indicating that the relative observation error was rather similar for every treatment.

Due to the low number of replicates and therefore high random variability in ratio estimates, considerable uncertainty about the true value of $\lambda$ remains. Therefore, we fitted a functional relationship regression for several $\lambda$-values (Figs. 1-4, Table 8). Based on the result that observation error variances for different soak time treatments are rather equal, the most likely functional relationship is the curve for $\lambda=1$. The curve for $\lambda=2$ represents an assumption that the observation error variance for the $y$-axis variable is 2-times that for the $\mathrm{x}$-axis variable, and for $\lambda=0.5$ the opposite. The true ratio of variances is not likely to be outside that range.
In contrast, the ordinary least squares (OLS) solution assuming no observation error for the $\mathrm{x}$-axis variable gives a seriously biased result, exacerbating the negative effect of accumulation for high $\mathrm{x}$-axis values. Moreover, it predicts that at low values of the $\mathrm{x}$-axis variable (shorter soak times), the typical catch for longer soak time is higher. This is clearly not logical, but a highly expected bias which can be explained simply by measurement errors in the $\mathrm{x}$-axis variable (in this particular case underestimation of the true value).

For FRR with $\lambda=1$ the residuals between observed and predicted values were not significantly different for different mesh sizes (ANOVA, all $\mathrm{p}>0.05$ ) in any pair of soak time treatments.

The accumulation effect was strongest when comparing the pair of longest and shortest treatments, $1^{*} 24 \mathrm{~h} v s .4^{*} 6 \mathrm{~h}$, (Fig. 1) but could be detected also for other pairs of less difference in soak time (Figs. $2 \&$ 3). Thus, the accumulation effect was evident already with a $12 \mathrm{~h}$ soak time.

Assuming an asymptotic relationship between the soak time treatment $U:$ s (with log-normal error structure) leads to even more biased interpretation in the OLS solution in comparison with FRR with $\lambda=1$ (Fig. 4, Table 8). For OLS, the net appears saturated when $U$ is about $1 \%$, whereas for $\lambda=$ 1 the saturation appears at about $2 \%$ (Table 8 ).

\section{DISCUSSION}

The simple nonparametric and parametric tests indicated clearly that the accumulation of fish negatively affects the catchability already between 6 and $12 \mathrm{~h}$ soak times at the fish density rate, sensu [10, 20], occurring in Lake Jyväsjärvi. Importantly, in our field test the effects of loss of some catch due to net lifting, disturbance and fouling were eliminated as far as possible to reveal the true effect of accumulation.

In the cases of highest fish density rate the nets may have already lost considerable catchability within $6 \mathrm{~h}$ and therefore the catch per unit effort might not be proportional to density even for this short soak time. When comparing $1 * 4 \mathrm{~h}$ with $4 * 1 \mathrm{~h}$ treatments, significant accumulation effect has been detected even within the first 4 hours [15]. When

Table 7. The estimated observation error variances of $\log P U$ for different mesh sizes and treatments and variance ratio $\lambda$.

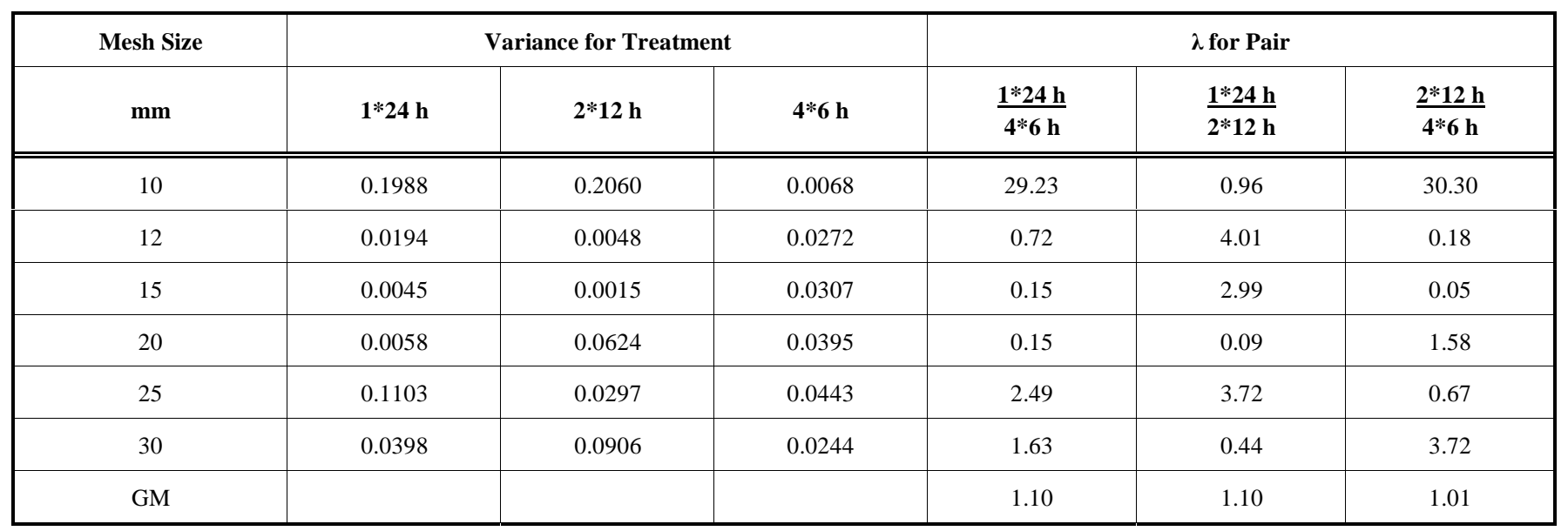




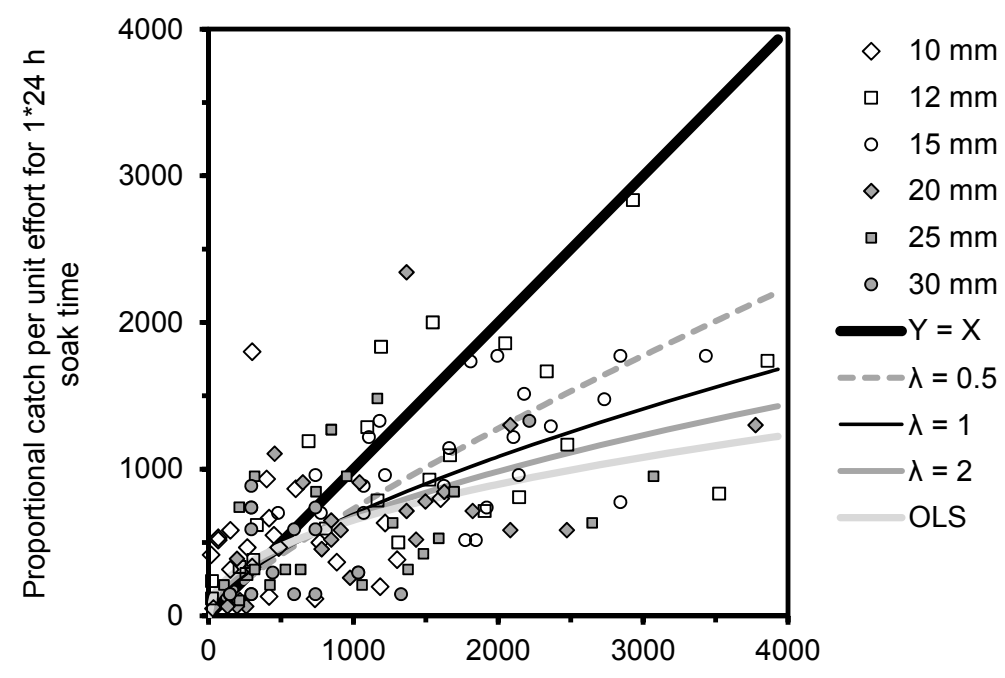

Proportional catch per unit effort for $4^{*} 6 \mathrm{~h}$ soak time

Fig. (1). The functional relationship regression power functions for different values of observation error variance ratio $\lambda$ fitted to mesh size specific pairs of proportional catch per unit effort during $24 \mathrm{~h}$ period from soak time treatment $1 * 24 \mathrm{~h}$ and $4 * 6 \mathrm{~h}$. OLS is ordinary least squares solution $(\lambda=\infty), \mathrm{Y}=\mathrm{X}$ is the line of equal values indicating no accumulation induced effect on catchability. Linear models were fitted to log-data. Parameter estimates are given in Table $\mathbf{8}$.

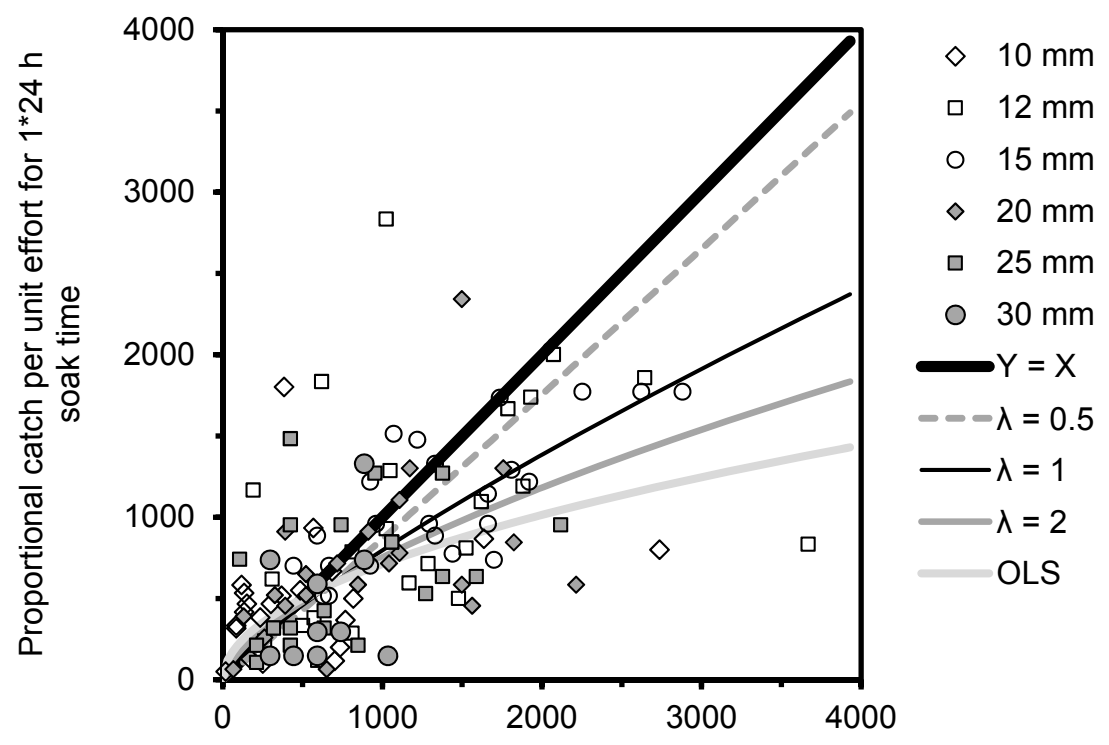

Proportional catch per unit effort for $2 * 12 \mathrm{~h}$ soak time

Fig. (2). The functional relationship regression power functions for different values of observation error variance ratio $\lambda$ fitted to mesh size specific pairs of proportional catch per unit effort during $24 \mathrm{~h}$ period from soak time treatment $1 * 24 \mathrm{~h}$ and $2 * 12 \mathrm{~h}$. OLS is ordinary least squares solution $(\lambda=\infty), Y=X$ is the line of equal values indicating no accumulation induced effect on catchability. Linear models were fitted along with log-data. Parameter estimates are given in Table $\mathbf{8}$.

comparing the results with other experiments it must be noted that different density rates, total fishing periods and soak times yield quantitatively different profiles. Also both the water colour [15] and the species composition (as shown in this study) affect the accumulation effect. However, after compensating for the different soak times and other methodological differences, the relative catches in this study are comparable with those in [15].
The use of FRR, assuming equal proportional observation (estimated for log-observations) error in both variables with $\lambda=1$, yielded very different curves in modelling in comparison to OLS-regression, which as expected exaggerated the accumulation effect. Thus, FRR can be recommended as a working standard for this sort of modelling approach. However, it must be emphasized that the correctness (accuracy) of the estimated model depends on the 


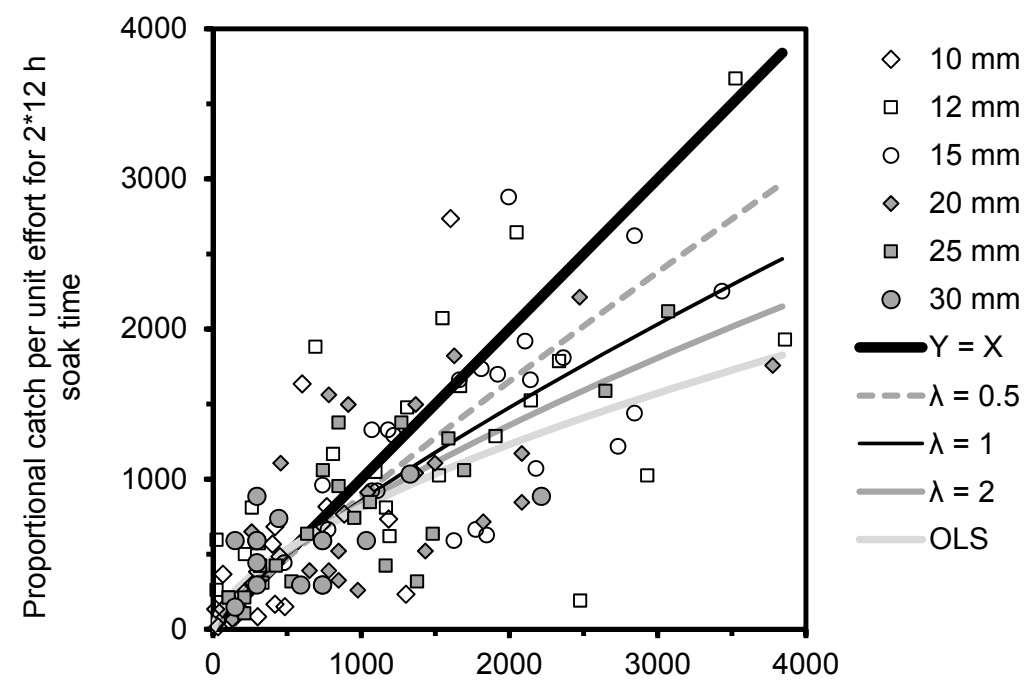

Proportional catch per unit effort for $4^{*} 6 \mathrm{~h}$ soak time

Fig. (3). The functional relationship regression power functions for different values of observation error variance ratio $\lambda$ fitted to mesh size specific pairs of proportional catch per unit effort during $24 \mathrm{~h}$ period from soak time treatment $2 * 12 \mathrm{~h}$ and $4 * 6 \mathrm{~h}$. OLS is ordinary least squares solution $(\lambda=\infty), \mathrm{Y}=\mathrm{X}$ is the line of equal values indicating no accumulation induced effect on catchability. Linear models were fitted to log-data. Parameter estimates are given in Table 8.

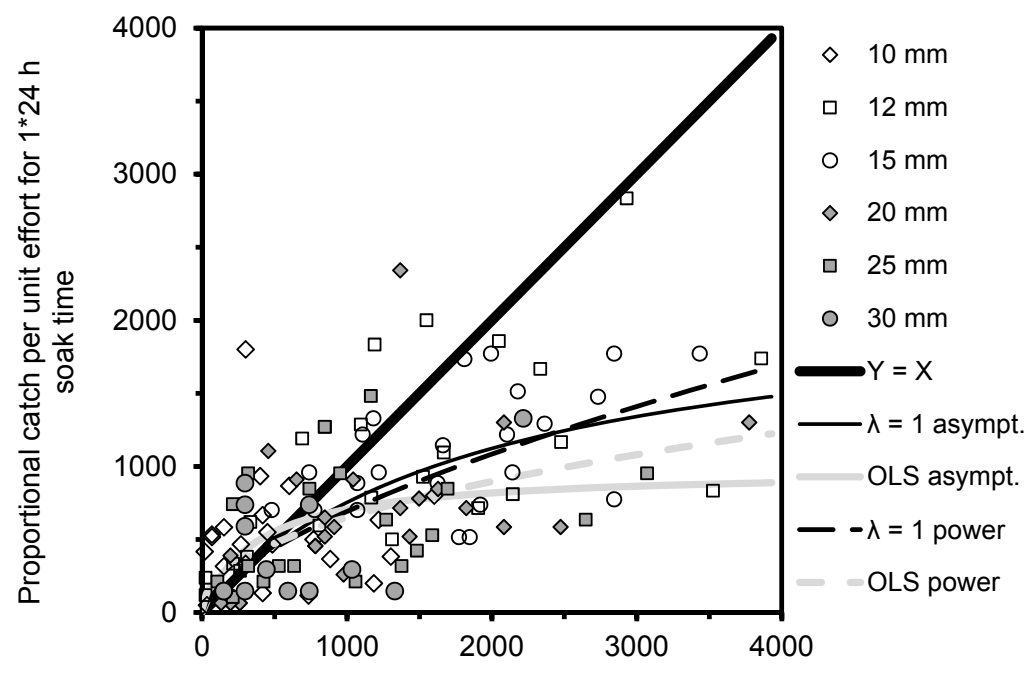

Proportional catch per unit effort for $4^{*} 6 \mathrm{~h}$ soak time

Fig. (4). The functional relationship regression solution with $\lambda=1$ for an asymptotic function in comparison with the OLS solution for power function for $1 * 24 \mathrm{~h}$ and $4 * 6 \mathrm{~h}$ treatments. For comparison of models, the power function solutions from Fig. (1) are also given. OLS is ordinary least squares solution $(\lambda=\infty), Y=X$ is the line of equal values indicating no accumulation induced effect on catchability. Models were fitted along with log-data. Parameter estimates are given in Table $\mathbf{8}$.

correctness of the estimate of the variance ratio $\lambda$. To our knowledge, no estimates of observation error variance, let alone variance ratios $\lambda$, for gill nets have been published previously. The present study did not yield very precise estimates either, even though we tried to estimate it in as homogenous as possible habitat. The number of replicates was unfortunately rather low due to the limited available areas judged as homogenous. Despite these shortcomings the result that the relative variances for different soak times were of the same order of magnitude sounds logical and accords with expectations, and thus to assume $\lambda=1$ (a so-called major axis solution) may be a reasonable $a$ priori assumption if the observation error variance is unknown.

Importantly also, the FRR must be recommended as a standard for any regression approach study comparing measurements from different density estimation methods, such as CPUEs from different gear, mark-recapture, removal, echo sounding and visual counts. Typical fish density proxies, whether relative or absolute, are estimates containing 
Table 8. The parameter estimates for the models given in figures $1-4$. Models were fitted along with log-data consistently. OLS = Ordinary Least Squares.

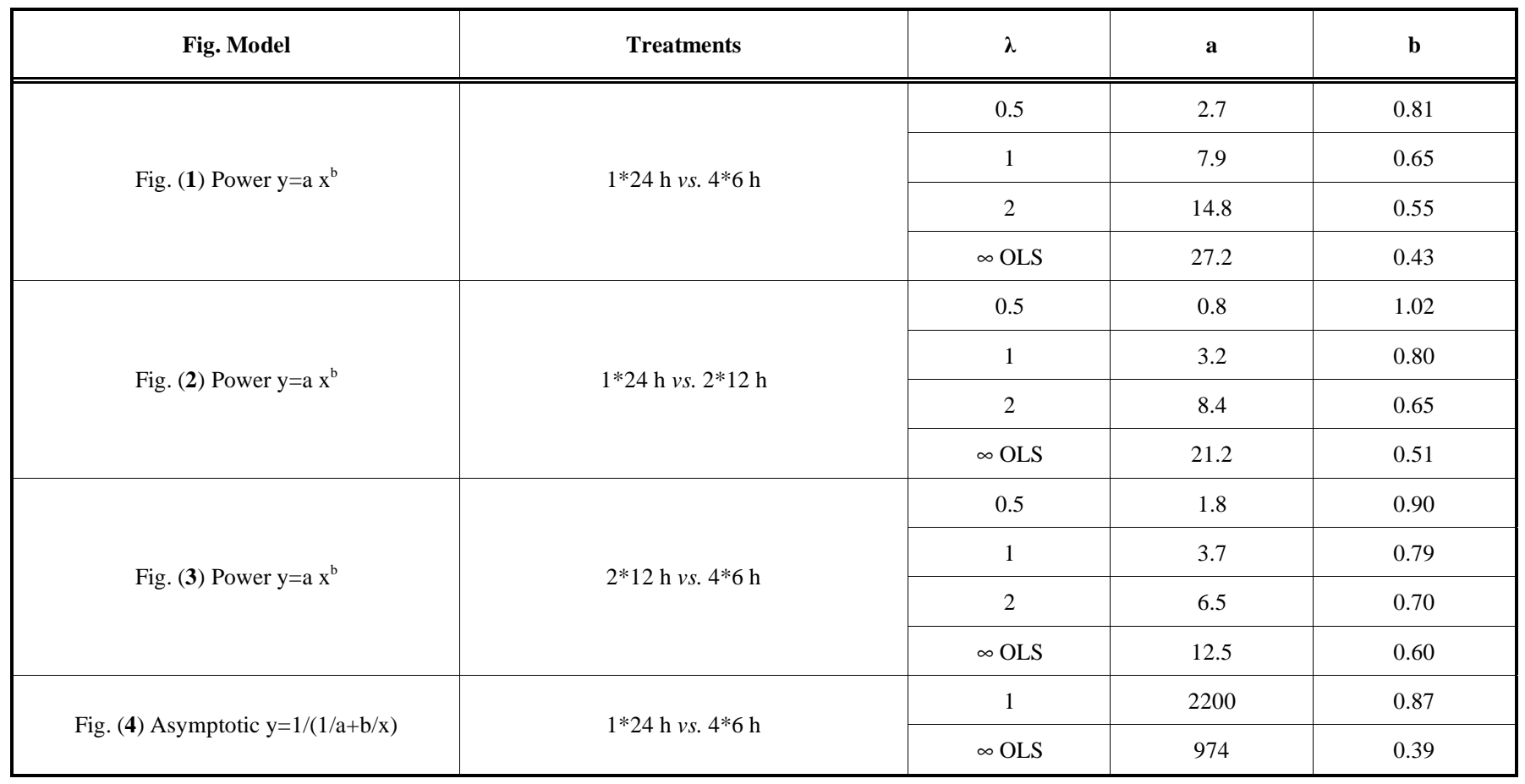

considerable observation error. Not taking these into account in the analysis may lead to seriously biased understanding of the correspondence between different methods.

Another cause of uncertainty in the regression approach is uncertainty about the correct model functional form. In our analysis we used a simple power function, which does not reach any asymptote, full saturation, although admittedly that must still be assumed possible, at least theoretically, with very long soak time and/or high density rate. However, the variability of the data is high which renders it difficult to determine any "correct" form for the relationship. One benefit of the power function is that it is easy to apply in practice because it can be reduced to a linear model assuming lognormality of error. Another benefit is that it is a bijective function for any positive $\mathrm{X}$-axis variable value and therefore its transfer function is a bijection as well. The transfer function is needed whenever attempting to eliminate the accumulation effect bias in CPUE induced by long soak time. The variability induced by observation error and true spatial variation in density in CPUE estimates from every individual gill net is too high for practical application of a transfer function but the annual whole lake average could be treated with it, as when trying to make results from a $24 \mathrm{~h}$ soak time more comparable with a $4 * 6 \mathrm{~h}$ soak time and thus more proportional to the true density rate. For example, the annual average of 20 gill nets using $24 \mathrm{~h}$ soak time which has been the standard for Lake Jyväsjärvi could be transformed to $4 * 6 \mathrm{~h}$ estimates whenever the $1 * 24 \mathrm{~h}$ catch is higher than the point of intersection between the model and line $y=x$, roughly above the level of 500 in Fig. (1).

For the Water Framework Directive [2], the assessment of ecological status of lakes based on fish assemblages is accomplished by experimental gill net fishing. In the Euro- pean standard [1] the recommended sampling period is $12 \mathrm{~h}$. According to the standard, bias induced by accumulation will occur when the $19 \mathrm{~mm}$ panel yield exceeds $120 \mathrm{~g} \mathrm{~m}^{-2}$ or the yield of the whole gill net exceeds $6 \mathrm{~kg}$. In those cases soak time should be reduced. Accumulation is measured by mass which does not take into account the number of fish or number of meshes occupied. Based on our and earlier studies the bias should be assessed based on the number of fish in the catch or the number of meshes used.

An interesting, yet for practical applications complicating, result was the finding that perch and roach had different accumulation effect responses, roach being more sensitive to accumulation. If this is true it must be taken into account when applying indices of lake ecological status based on fish assemblages e.g., EQR4 [27]. Moreover, gillnet sampling overestimates the proportion of percids in relation to cyprinids [28] increasing the bias. The species-specific features can be complicated to model, as the accumulation effect might be a function of density and activity of the species itself or affected also by several other species with different effect sizes and, therefore, beyond the scope of this study. Other comparable studies $[15,20]$ did not report any symptoms of prominent changes in species proportions when comparing data for $1 * 12 \mathrm{~h}$ vs. $3 * 4 \mathrm{~h}$ treatments and overnight vs. $1 \mathrm{~h}$ treatments, respectively. Contrary to our findings, even decreasing catchability with increasing density particularly for perch and to a lesser extent with roach has been found [9]. These species-specific differences definitely require further study.

\section{CONFLICT OF INTEREST}

The authors confirm that this article content has no conflict of interest. 


\section{ACKNOWLEDGEMENTS}

Prof. Roger I. Jones, University of Jyväskylä, has kindly checked the language.

\section{REFERENCES}

[1] European Committee for Standardization. European Standard EN 14757:2005: E. Water quality - sampling of fish with multimesh gillnets: European Committee for Standardization 2005.

[2] European Commission. Directive 2000/60/EC of the European Parliament and of the Council of 23 October 2000 establishing a framework for community action in the field of water policy. Official Journal of the European Communities 2000; L327: 1-73.

[3] Ricker WE. Relation for "catch per unit effort" to abundance and rate of exploitation. J Fish Res Board Can 1940; 5: 43-70.

[4] Ricker WE. Further notes on fishing mortality and effort. Copeia 1944; 1944(1): 23-44.

[5] Henderson BA, Collins JJ, Reckahn JA. Dynamics of an exploited population of lake whitefish (Coregonus clupeaformis) in Lake Huron. Can J Fish Aquat Sci 1983; 40: 1556-67.

[6] Crecco VA, Savoy TF. Density-dependent catchability and its potential causes and consequences on Connecticut River American shad, Alosa sapidissima. Can J Fish Aquat Sci 1985; 42: 1649-57.

[7] Angelsen KK, Olsen S. Impact of fish density and effort level on catching efficiency of fishing gear. Fish Res 1987; 5: 271-8.

[8] Borgstrøm R. Effect of population density on gillnet catchability in four allopatric populations of brown trout (Salmo trutta). Can J Fish Aquat Sci 1992; 49: 1539-45.

[9] Linløkken A, Haugen TO. Density and temperature dependence of gill net catch per unit effort for perch, Perca fluviatilis, and roach, Rutilus rutilus. Fish Manag Ecol 2006; 13: 261-9.

[10] Prchalová M, Mrkvička T, Peterka J, Berec L, Kubečka J. A model of gillnet catch in relation to the catchable biomass, saturation, soak time and sampling period. Fish Res 2011; 107: 201-9.

[11] Hamley JM. Review of gillnet selectivity. J Fish Res Board Can 1975; 32: 1943-69.

[12] Kennedy WA. The relationship of fishing effort by gill nets to the interval between lifts. J Fish Res Board Can 1951; 8: 264-74.

[13] Koike A, Takeuchi S. Saturation of gill-net for pondsmelt, hypomesus transpacificus nipponensis. Bull Jpn Soc Sci Fish 1982; 48: 1711-6.
[14] Hickford MJH, Schiel DR. Gillnetting in southern New Zealand: duration effects of sets and entanglement modes of fish. Fish Bull 1996; 94: 669-7.

[15] Olin M, Kurkilahti M, Peitola P, Ruuhijärvi J. The effects of fish accumulation on the catchability of multimesh gillnet. Fish Res 2004; 68: 135-47.

[16] Van Oosten J. Logically justified deductions concerning the Great Lakes Fisheries exploded by scientific research. Trans Am Fish Soc 1935; 65: 71-5.

[17] Hewson LC. Study of nylon and cotton gill-nets. Dept Fish Can, Trade News 1952; 4(12): 3-4.

[18] von Brandt J. Enmeshing nets: gillnets and entangling nets - the theory of their efficiency. EIFAC Tech Pap 1975; 23 Suppl.1, vol 1: 96-116.

[19] Von Brandt A. The efficiency of drift-nets. J Cons Int Explor Mer 1955; 21: 8-16.

[20] Prchalová M, Peterka J, Čech M, Kubečka J. A simple proof of gillnet saturation. Boreal Environ Res 2013; 18: 303-8.

[21] Kendall MG, Stuart A. The advanced theory of statistics, volume 2. Inference and relationship. London: Gharles Griffin 1967.

[22] Walters CJ, Ludwig D. Effects of measurement errors on the assessment of stock-recruitment relationships. Can J Fish Aquat Sci 1981; 38: 704-10.

[23] Kimura DK. Using nonlinear functional relationship regression to fit fisheries models. Can J Fish Aquat Sci 2000; 57: 160-70.

[24] Sprent P, Dolby R. Response to the query about the geometric mean functional relationship. Biometrics 1980; 36: 547-50.

[25] Salonen K, Karjalainen J, Högmander P, Keskinen T, Huttula T, Palomäki A. Recovery of Lake Jyväsjärvi after pollution by municipal and industrial waste waters. Verh Internat Limnol 2005; 29: 619-22.

[26] Jensen JW. Gillnet selectivity and the efficiency of alternative combinations of mesh sizes for some freshwater fish. J Fish Biol 1985; 28: 637-46.

[27] Rask M, Olin M, Ruuhijärvi J. Fish-based assessment of ecological status of Finnish lakes loaded by diffuse nutrient pollution from agriculture. Fish Manag Ecol 2010; 17: 126-33.

[28] Prchalová M, Kubečka J, Říha M, et al. Overestimation of Percid fishes (Percidae) in gillnet sampling. Fish Res 2008; 91: 79-87.

Received: August 08, 2014

Revised: June 01, 2015

Accepted: June 16, 2015

(C) Marjomäki et al.; Licensee Bentham Open.

This is an open access article licensed under the terms of the (https://creativecommons.org/licenses/by/4.0/legalcode), which permits unrestricted, noncommercial use, distribution and reproduction in any medium, provided the work is properly cited. 